\title{
The Development of Fatigue Cracks in Metals
}

\author{
Dariusz Rozumek \\ Opole University of Technology, Mikolajczyka 5, 45-271 Opole, Poland \\ d.rozumek@po.opole.pl
}

\section{Keywords: Fatigue Crack Growth, Microstructure, Load, Mixed Mode}

\begin{abstract}
The work presents the development of fatigue cracks in metals (review article). In particular, the reasons for the growth of fatigue cracks, models of the development of cracks, cracks initiation and propagation for various modes as well as effects of the cracks growth were presented. Fatigue of materials, especially the formation of fatigue cracks and their growth, belong to the important problems of solid mechanics. Designers and constructors of machines and industrial devices are focusing their attention on problems concerning durability and reliability of these devices. Therefore, the engineering materials that are used to construct devices should have the best properties, because choosing the right material affects, to a large extent, the durability of construction.
\end{abstract}

\section{Introduction}

Fatigue of the material occurs under the influence of variable loads (stresses) over time, which are typical in various machine systems $[1,2,3]$. It is a very important phenomenon as it is the main culprit behind about $90 \%$ of damaged machine parts [4]. This process occurs through nucleation and crack growth.

Mechanics of fracture is a relatively young science branch. Its development took place during the Second World War. One of the reasons for interest in this phenomenon was the failure of the "Liberty" type ships. The development of fatigue cracks in those ships concerned brittle fracture, which occurred due to existing material defects in the welding process. Brittle fracture is very dangerous due to the very rapid cracks growth and cause the greatest material losses compared to other types of fractures (ductile, mixed) [4]. Three parameters are used to describe fatigue crack growth: stress, displacement and energy. The stress parameter describes the stress state near the crack tip in brittle materials with an error of 5 - 20\% compared to elastic-plastic materials for the stress range $0.4 \sigma_{\mathrm{y}}<\sigma<0.7 \sigma_{\mathrm{y}}$ [4]. The displacement parameter is described with the use of the crack tip opening displacement $\delta$. Since the crack tip opening displacement (CTOD) is a certain measure of strains in the area near the tip, it is also called a "strain parameter". This parameter is applied for the elastic-plastic materials to the yield point $\sigma_{\mathrm{y}}$. The energy based parameters use the strain energy density and the J-integral [5].

The aim of the paper is to present the causes of fatigue cracks growth, models for its description, as well as test results and effects caused by cracks on examples of structural damage.

\section{Causes of fatigue cracks}

Structure and surface of the material

One of the reasons for the development of fatigue cracks are point and linear crystal defects (dislocations) [6-8]. We can distinguish four types of point defects in the material (see Fig. 1) as: an atom of a foreign element - 1, additional atom of a foreign element - 2, void (lack of atom) 3 , indigenous atom in the wrong place - 4 . There are two types of dislocations: edge (presence of an additional crystalline half-plane) and screw (displacement of a part of the crystal). Dislocations are usually mixed. In areas of special dislocation concentration, slip bands may 
occur. There are plastic strains in the slip bands. They are related to the strains inside the crystals, which may be elastic or plastic. Elastic strains cause tension, which disappears after removing the load. Plastic strains break the atomic bonds, as a result of which the atoms gain new neighbors. Plastic strains do not occur in the whole volume of the crystal, but as a dislocation movement most conveniently oriented relative to the $\tau_{\max }$. As a result, followed by a break of only some atomic bonds. Metals can be divided into elastic and plastic based on their mechanical properties.

a)

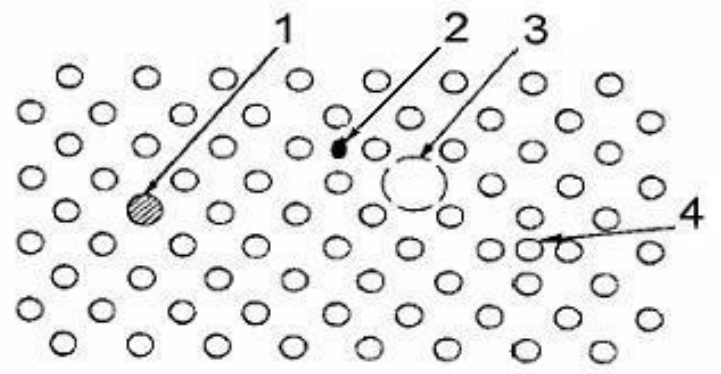

b)

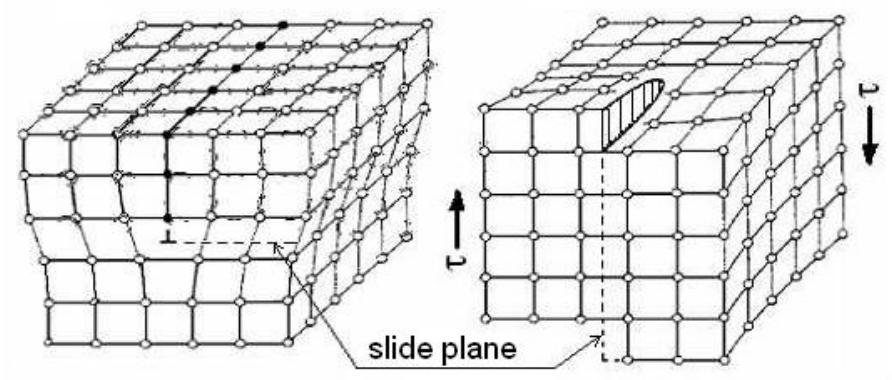

Fig. 1. Types of point defects in the crystal lattice of the metal a), two types of dislocations: $b$ ) edge, c) screw [9]

Elastic metals (among others brittle) have a high strength and as a result: (i) have few slip bands, (ii) the initiations of microcracks are in the places of defects, (iii) microcracks are less common than in ductile metals, (iv) the increase in size of microcracks occur in planes perpendicular to the load, and (v) microcracks connect into macrocracks. Plastic (ductile) metals have low strength and as a result one can see that: (i) the number of slip bands increases with the number of cycles up to the saturation level, (ii) the development of plastic strains occurs only in some slip bands, (iii) some of the slip bands are transformed into microcracks inside a crystal structure, (iv) microcracks growth and connect up to the appearance of macroscopically visible cracks (length about $\left.10^{-1} \mathrm{~mm}\right)$, (v) the growth of macrocracks causes damage.

\section{Load and environment}

Cracks in the material are caused by occurring stresses during load (Fig. 2a). More precisely, the lack of stresses relaxation at the tip of the crack due to dissipation processes (development of plastic strains), which causes the slip bands in the direction of $\tau_{\max }$.

a)

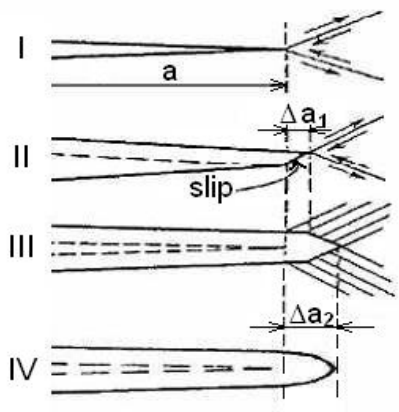

b)

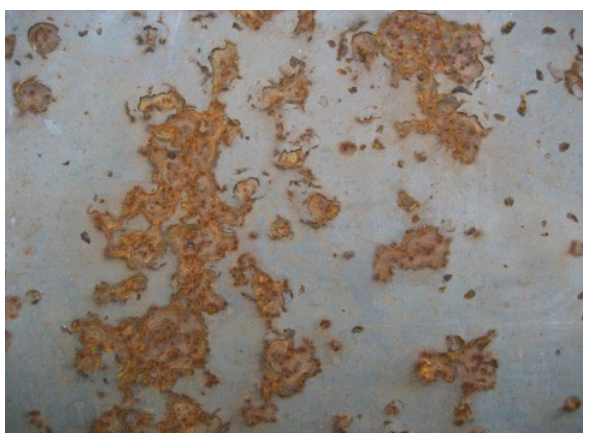

Fig. 2. Mechanism of fatigue cracks growth a), steel surface with defects caused by corrosion b) 
The effect of this is crack growth by $\Delta \mathrm{a}$ (Fig. 2a). The creation of new slip bands results in a further increases in the crack and blunting (rounding) of its tip. After unloading, the process is repeated until damage occurs. Crack growth is often accelerated by the influence of the environment (eg. corrosion - Fig. 2b) to which the material is exposed. It causes the oxidation of the material and the formation of defects creating cracks, pits and etc. Corrosion acceleration can occur under the influence of moisture, as well as chlorine or sulfur. In addition, the corrosion rate is affected by the temperature and the higher it is, the faster the processes take place. With simultaneous stresses and corrosion, the crack growth is more intense.

\section{Models to describe fatigue cracks}

In addition to brittle and ductile fracture, we can divide the cracking based on the Wöhler curve. The fatigue crack growth may be in the low cycle fatigue (LCF) and high cycle fatigue (HCF) range. In the case of LCF, initiation and propagation occurs from the beginning of the process (Fig. 3a), and for HCF, initiation and cracks growth occurs at the end of element life (see Fig. 3b) [10].

a)

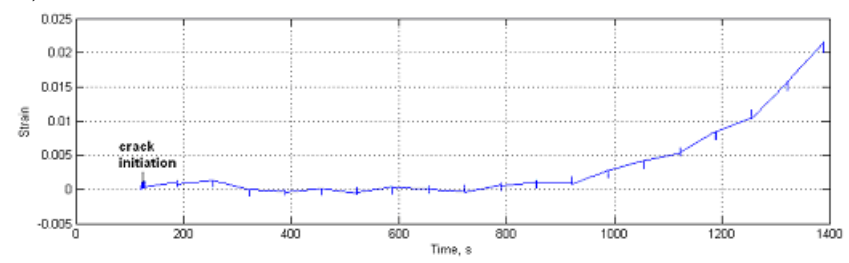

b)

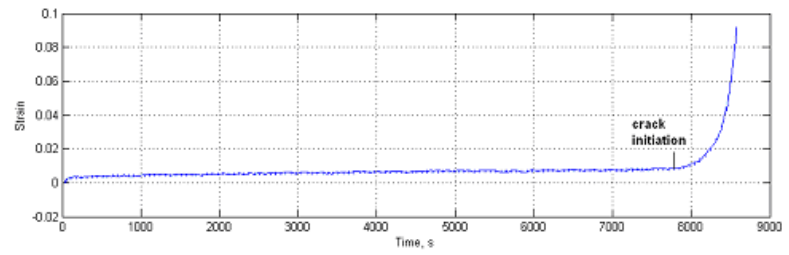

Fig. 3. Crack initiation point for a) LCF, b) HCF

Irwin proposed in 1957 [11] the stress intensity factor (SIF) represented by the variable, K. SIF describes the stress state at a crack tip, is related to the crack growth rate, and is used to establish the failure criteria due to fracture. According to Irwin's proposal, there exist three types of loading: mode I - tensile opening, mode II - in-plane sliding, mode III - tearing or anti-plane shear [5]. SIF was used to create curves of fatigue crack growth rate. One of the first was Paris [12], who proposed for linear elastic fracture mechanics (LEFM) relation

$$
\mathrm{da} / \mathrm{dN}=\mathrm{C}(\Delta \mathrm{K})^{m}
$$

where $\mathrm{C}$ and $\mathrm{m}$ are material constants determined experimentally. The main weakness of the Paris law is a fact that it does not take into account the effect of mean stress, what Forman [13] noticed, and proposed the equation with an additional critical value $\mathrm{K}_{\mathrm{c}}$ (fracture toughness) and stress ratio $\mathrm{R}$

$$
\mathrm{da} / \mathrm{dN}=\frac{\mathrm{C}(\Delta \mathrm{K})^{m}}{(1-\mathrm{R}) \mathrm{K}_{\mathrm{c}}-\Delta \mathrm{K}}
$$

The next modification of Eq. (1) was done by Elber taking into account the crack closing and opening. Priddle was one of the first who proposed a description of the entire crack kinetics curve. The next authors were McEvily and Yarema, whose proposals can be found in the paper [14]. Depending on the applied stress, strain (crack-tip opening displacement - CTOD), or energy approach, the fatigue crack growth rate can be represented as a function of one of the mentioned parameters. For example in Ref. [14], the author proposed an equation for the description of the 
total curve of crack growth kinetics versus the energy parameter range $\Delta \mathrm{J}$, i.e. from the range of the threshold value $\Delta \mathrm{J}_{\text {th }}$ to the critical value of the parameter $\mathrm{J}_{\text {Ic }}$.

$$
\mathrm{da} / \mathrm{dN}=\mathrm{B}\left[\frac{\Delta \mathrm{J}-\Delta \mathrm{J}_{\mathrm{th}}}{(1-\mathrm{R})^{2} \mathrm{~J}_{\mathrm{Ic}}-\mathrm{J}_{\max }}\right]^{n},
$$

where $\mathrm{B}$ and $\mathrm{n}$ are experimental coefficients, and $\mathrm{J}_{\max }$ is the maximum value of parameter $\mathrm{J}$.

\section{The development of fatigue cracks}

The development of fatigue cracks were carried out on the machines shown in Figs 4 and 5. Fig. 4a shows the fatigue test stand MZPK 100 [15] for cruciform specimens (mixed mode I+II), which allows to conduct fatigue experiments under cyclic and random loading, also with a static mean value. In the holed specimen, made of S355 steel, shown in Fig. 4b, the cracks developed for mode I. In the solid specimen shown in Fig. 4c the cracks developed for mixed mode I+II then for mode I. The MZGS-100 stand [16,17] for testing the fatigue crack growth during

a)

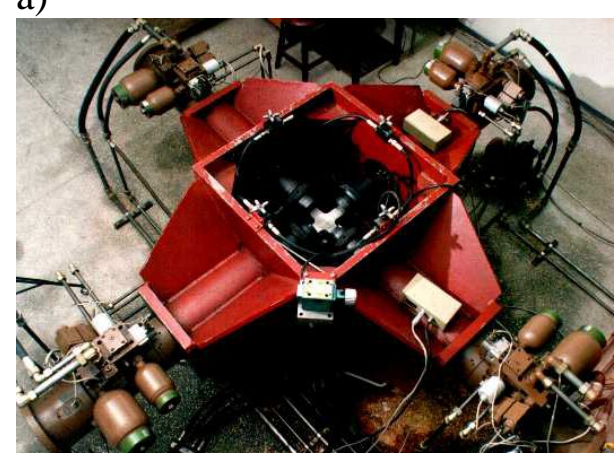

b)

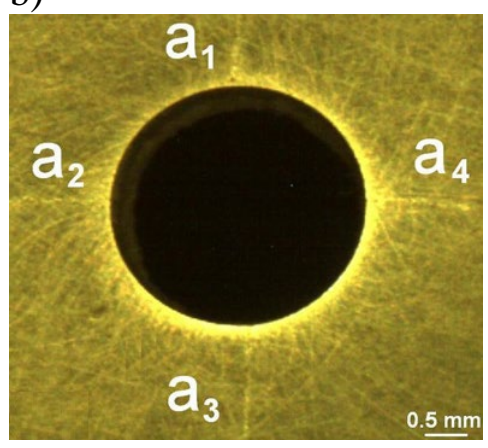

c)

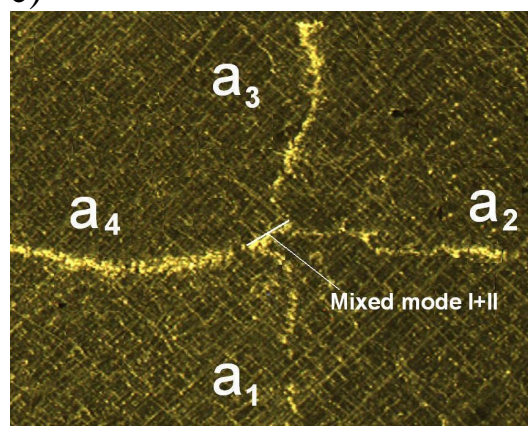

Fig. 4. The MZPK-100 fatigue stand setup a), crack growth in specimens: b) with hole, c) without hole

proportional bending with torsion (mixed mode I+III) and additional static (mean) load (Fig. 5a). The specimen load for combination of bending with torsion $\left(\mathrm{M}_{\mathrm{BT}}\right)$ is shown in Fig. 5b.

a)

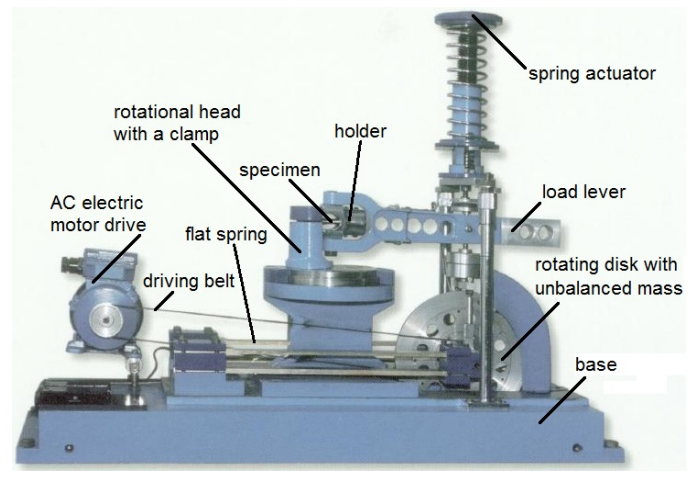

b)

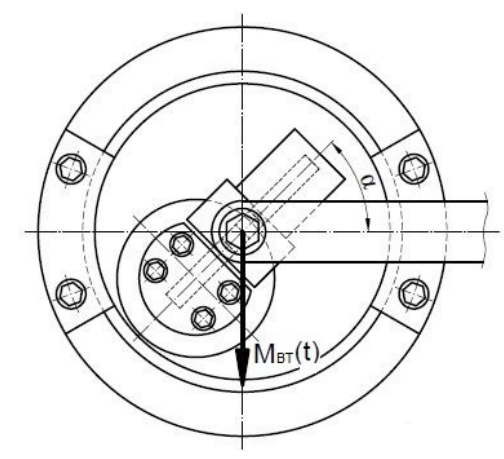

Fig. 5. The MZGS-100 fatigue stand setup a), loading of the specimen b) 
The length of the crack versus the number of cycles is used to describe the fatigue cracks growth. Depending on the applied load or occurring notches [18], the growth of cracks may have a different lifetime. Fig. 6 presents the fatigue cracks length versus the number of cycles for S355 steel under a different values of the bending moment amplitudes $\left(\mathrm{M}_{\mathrm{a}}\right)$ and various notches $\left(\mathrm{K}_{\mathrm{t}}\right)$. From Fig. 6 it appears that an increase of the bending moment and change the notch root radii from blunt to sharp causes a decrease in the fatigue life of the tested specimens.

a)

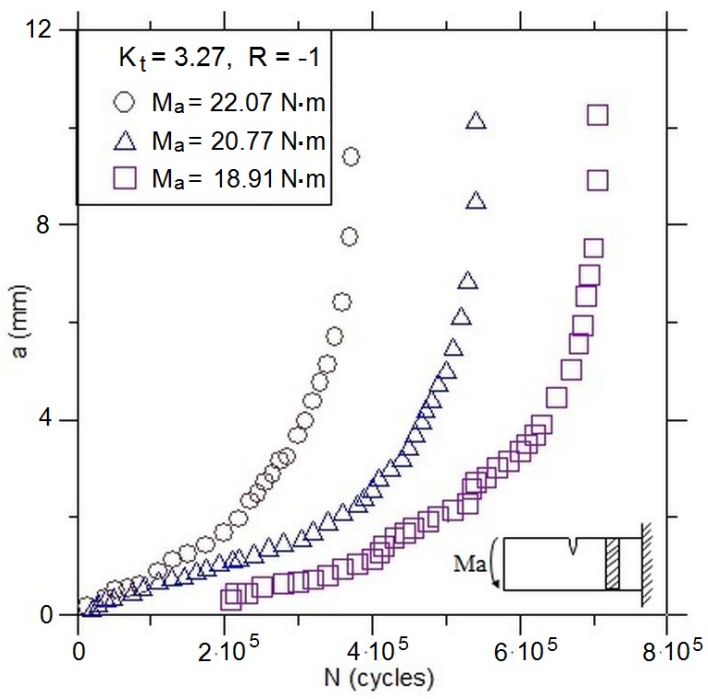

b)

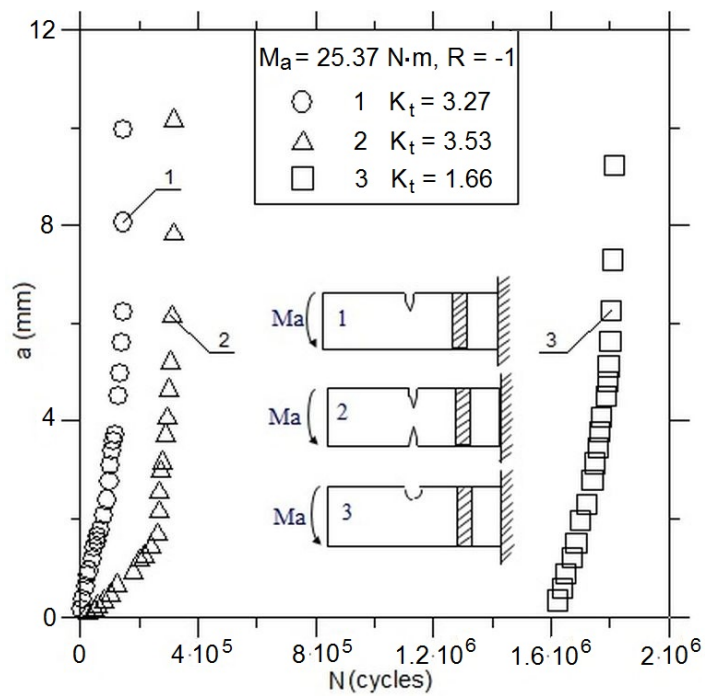

Fig. 6. Fatigue crack lengths versus the number of cycles for different a) loads, b) notches

\section{The effects of the fatigue cracks growth}

The growth of fatigue cracks lead to damage or destruction of the object or structure. The effects of fatigue cracks are observed on the examples of various disasters. Damage of Liberty ships is one of the most frequently cited examples of brittle fractures. The need for fast and cheap to build ships during the Second World War resulted in the replacement of sheet metal riveting with welding, which significantly accelerated the production of ships (until 1946, about 4,000 ships were built). In the years 1941-1953, there were 1250 ships damaged by brittle fractures, of which 12 ships broke into two parts. Research on the cause of the damage ships began when one of the ships in a dry dock in the shipyard in Kensington Bay broke in a half. These cracks occurred in places of stress concentration (most often in the middle of the ship), and their development was initiated by welding defects (the used material had very low impact resistance at low temperatures). There are various other examples such as the sinking of the oil platform Alexander Kielland, as well as some plane crashes, train accidents and bridge disasters. The cause of loss of stability of the Kielland oil platform was a fatigue fracture of the reinforcing element to which the hydrophone was welded. In the years 1952-1954 a series of plane crashes with the use of the Comet aircraft resulted in many deaths. Experimental research with variable pressure differences across the entire Comet plane structure showed the appearance of cracks in the aircraft fuselage near the windows and safety exits. In 1980, a plane crashed near the Okęcie airport, in which 77 passengers and 10 crew members were killed. The cause was a fatigue fracture of the engine shaft. In 1998, a passenger train in Eschede (Germany) derailed, in which 101 people were killed and 88 injured. The cause of the derailment of the train was fatigue damage to one of the wagon wheels. Another train derailed in Spain (in 2001) where 5 passengers were injured. The cause was the fatigue fracture of the rail under the train. In 2007, a 
truss bridge over the Mississippi River collapsed. The reason was the corrosion of metal elements and material fatigue which caused the bridge to lost its flexibility.

\section{Summary}

Fatigue microcracks usually appear on the surface or in the surface layer of an object. In only a few cases, e.g. in surface-improved elements, the microcracks can develop on the edge of the core and the hardened layer. Similarly, in elements with galvanic coatings, it is possible to initiate cracks at the boundary of the substrate and coating. The sources of microcracks are also non-metallic inclusions and surface defects of technological origin. Nucleation of fatigue crack occurs at the tip of microcracks. It develops initially in the plane experiencing maximum tangential stresses. The development of fatigue cracks in a corrosive environment is different than in an inert environment. This manifests itself in different reactions compared to material working in a corrosive and neutral environment to changes in the parameters of mechanical loads. The development of fatigue cracks is common in constructions and devices, the effect of which is failure or damage (destruction) of the structure. It causes large financial losses. In many cases, deaths and disability have been caused by the development of fatigue cracks. Statistics show that in the United States loses reach 100 million dollars a year. The main reasons for the development of fatigue cracks (according to British statistics) are: stress concentrators, surface quality, wrong choice of material and not sufficient design experience.

\section{References}

[1] S. Suresh, Fatigue of Materials, Cambridge University Press, Cambridge, UK, 1991.

[2] J. Gadomski, P. Pyrzanowski, Experimental investigation of fatigue destruction of CFRP using the electrical resistance change method, Measurement. 87 (2016) 236-245.

https://doi.org/10.1016/j.measurement.2016.03.036

[3] L. Sniezek, T. Slezak, K. Grzelak, V. Hutsaylyuk, An experimental investigation of propagation the semi-elliptical surface cracks in an austenitic steel, Int. J. Pressure Vessels and Piping. 144 (2016) 35-44. https://doi.org/10.1016/j.ijpvp.2016.05.006

[4] S. Kocańda, Fatigue Failure of Metals, WNT, Warsaw, 1985.

[5] D. Rozumek, E. Macha, A survey of failure criteria and parameters in mixed-mode fatigue crack growth, Materials Science. 45 (2009) 190-210. https://doi.org/10.1007/s11003-009-9179-2

[6] U. Zerbst, M. Madia, C. Klinger, D. Bettge, Y. Murakam, Defects as a root cause of fatigue failure of metallic components. I: Basic aspects, Eng. Failure Analysis. 97 (2019) 777-792. https://doi.org/10.1016/j.engfailanal.2019.01.055

[7] P. Lukas, L. Kunz, Notch size effect in fatigue, Fatigue Fract. Eng. Mater. Struct. 12 (1989), 175-186. https://doi.org/10.1016/0142-1123(89)90261-2

[8] C. Verdu, J. Adrien, J.Y. Buffiere, Three-dimensional shape of the early stages of fatigue cracks nucleated in nodular cast iron, Mater. Sci. Eng. A. 483-484 (2008), 402-405.

[9] K. Przybyłowicz, J. Przybyłowicz, Repetytorium z materiałoznawstwa, cz. II, Fizyczne podstawy materiałoznawstwa, Politechnika Świętokrzyska, Skrypt nr 279.

[10] D. Rozumek, Z. Marciniak, Fatigue properties of notched specimens made of FeP04 steel, Materials Science. 47 (2012) 462-469. https://doi.org/10.1007/s11003-012-9417-X 
[11] G.R. Irwin, Analysis of stresses and strains near the end of a crack traversing a plate, Journal of Applied Mechanics. 24 (1957) 361-364.

[12] P.C. Paris, F. Erdogan, A critical analysis of crack propagation laws, J. of Basic Eng., Trans, American Society of Mechanical Engineers. 85 (1960) 528-534.

[13] R.G. Forman, V.E. Kearney, R.M. Engle, Numerical analysis of crack propagation in cyclicloaded structures, Journal of Basic Eng., ASME. 89 (1967) 459-464. https://doi.org/10.1115/1.3609637

[14] D. Rozumek, Survey of formulas used to describe the fatigue crack growth rate, Materials Science. 49(6) (2014) 723-733. https://doi.org/10.1007/s11003-014-9667-x

[15] D. Rozumek, C.T. Lachowicz, E. Macha, Analytical and numerical evaluation of stress intensity factor along crack paths in the cruciform specimens under out-of-phase cyclic loading, Engineering Fracture Mechanics. 77 (2010) 1808-1821.

https://doi.org/10.1016/j.engfracmech.2010.02.027

[16] J. Lewandowski, D. Rozumek, Cracks growth in S355 steel under cyclic bending with fillet welded joint, Theoretical and Applied Fracture Mechanics. 86 (2016) 342-350. https://doi.org/10.1016/j.tafmec.2016.09.003

[17] D. Rozumek, Z. Marciniak, Control system of the fatigue stand for material tests under combined bending with torsion loading and experimental results, Mechanical Systems and Signal Processing. 22 (2008) 1289-1296. https://doi.org/10.1016/j.ymssp.2007.09.009

[18] G. Robak, D. Krzyzak, A. Cichanski, Determining effective length for 40 HM-T steel by use of non-local line method concept, Polish Maritime Research. 25 (2018) 128-136. https://doi.org/10.2478/pomr-2018-0015 